\title{
The Correlation Between The COVID-19 Infection Severity and ABO Blood Groups in Sulaimaniyah City, Iraq
}

Nazaneen Omer ( $\sim$ nazaneen.omer@univsul.edu.iq )

University of Sulaimani

Sarwer Ismael

University of Sulaimani College of Medicine

Heshu Sulaiman Rahman

University of Sulaimani College of Medicine https://orcid.org/0000-0003-0356-0399

Maryam Mohammed

University of Sulaimani College of Medicine

\section{Research}

Keywords: COVID-19, infection severity, ABO Blood Group, Rh group

Posted Date: November 15th, 2021

DOI: https://doi.org/10.21203/rs.3.rs-987148/v1

License: (a) (i) This work is licensed under a Creative Commons Attribution 4.0 International License.

Read Full License 


\section{Abstract \\ Background}

ABO blood group types are among the risk factors of COVID-19 infection in many recent studies. Thus, the objective of this study is to find the relations between ABO types and COVID-19 infection as well as to find out the riskier group that is associated with hospitalization and the need for $\mathrm{O}_{2}$ support.

\section{Methods}

This observational cross-sectional study was done to identify the risk and relations between ABO blood groups and Rh factor of 530 Iraqi-Kurdish patients affected with COVID-19 infection. Among them, 184 patients were severe cases that needed hospitalization while 346 patients were mild to moderate cases that were treated at home. The diagnosis of COVID-19 infection was based on Real-Time Polymerase Chain Reaction (RT-PCR) test, high-resolution Chest CT scan, strong clinical suspicion plus history of the close home or job contact with COVID-19 confirmed patient.

\section{Results}

There were no significant differences in the distribution of $A B O$ blood grouping in the total COVID-19 cases, however, the severity in form of hospitalization and $\mathrm{O}_{2}$ demand was higher in blood group $\mathrm{A}$ whereas the lowest in group B. Male patient were significantly older than females with more prolonged illness duration. The duration of COVID-19 illness, the need for plasma, and the rate of mortality were very significantly higher among hospitalized COVID-19 patients than non-hospitalized. In $37.2 \%$ of the patient, the initial presentation was a combination of more than one symptom. In $28 \%$ of cases, myalgia was the 1st mono-symptomatic presentation.

\section{Conclusions}

Blood group $A$ is associated with the highest rate of hospitalization and $\mathrm{O}_{2}$ demand, besides, the duration of illness and rate of mortality in males were more than females.

\section{Background}

The new SARS-CoV2 (COVID-19) is a rapidly spreading infection that is regarded by WHO as a pandemic $(1$ - 3). The COVID-19 is produced by enclosed RNA which belongs to the family Coronaviridae and are frequently spherical assumed electron microscopic morphology (4).

Types of $A B O$ blood groups are among the risk factors in many current studies. The relations of the $A B O$ typing with the severity of COVID-19 symptoms, risk of hospitalization, and ventilator support is a subject 
for study and exploration (5 - 7). In the previous 20 years, there has been enhancing evidence that blood groups have roles and play many biological functions in some disease development and progress. These biological functions often do not transmit to the red cell alone, but to other chemical moieties on other cells that were primarily recognized as red cell antigens. Antigens, first recognized on RBCs, are now identified to be important as ligands and receptors for parasites, bacteria, immunologically important proteins, and viruses (8).

There are some irrefutable relations of blood groups with some diseases like peptic ulcers, malignancy, coagulation, and viral infection (9). Some researchers have recommended that the ABO blood group antigens should be called $\mathrm{ABH}$ histo-blood group antigens to accentuate that they are primarily tissue antigens (10).

Instantly, susceptibility of certain viral infections has been related to antigenic elements of ABO blood groups (11). Cheng et al. showed a relation of SARS coronavirus infection with ABO blood groups (12). Understanding the various phases of presentation and the multitude of risk factors of its susceptibility help health care professionals for early diagnosis and better management plan (13).

As, ABO blood group types are among the risk factors in many recent studies $(6,7,14)$, this current study aimed to find the relations between blood group types and COVID-19 infection as well as to identify the more risky blood groups that associated with hospitalization and need for $\mathrm{O}_{2}$ support.

\section{Methods}

\section{Study setting and data collection}

This observational cross-sectional study was planned to assess the blood group and $\mathrm{Rh}$ factor of 530 Iraqi (Kurdish) patients affected with COVID-19 infection. Among them, 184 patients were severe cases that needed hospitalization, and 346 mild to moderate cases that were treated at home without $\mathrm{O}_{2}$ supplementation. The data were collected from Qala (at Kalar province), Shaheed Aso, and Shaheed Hemn hospitals for Corona in Sulaimaniyah city in the Iraqi Kurdistan region from August 2020 till November 2020.

\section{Patient's diagnosis strategy}

Patients with COVID-19 infection that were enrolled in this study were diagnosed based on the following techniques:

\section{RT-PCR test}

This test established on the first sequences of SARS-CoV-2 complete available on the GISAID database probes and primers ( $\mathrm{nCoV}_{\mathrm{I}} \mathrm{IP} 2$ and $\mathrm{nCoV}$ IIP4) were intended to target the RdRp gene straddling nt 1262112727 and 14010-14116 (positions rendering SARS-CoV, NC_004718)(15). 


\section{High-resolution chest computed tomography (HRCT)}

HRCT is a scanning protocol in which thin sections (usually $0.625-1.25 \mathrm{~mm}$ ) are acquired and reconstructed using a sharp algorithm (e.g. bone algorithm). Patients stated for CT were experience noncontrast high-resolution chest CT (16).

\section{Strong clinical suspicion plus history of close home or job contact with COVID-19 confirmed patient}

The following data were collected from the patients on a predesigned questioner form: age, gender, $1^{\text {st }}$ presenting symptom(s), duration of illness, history of contact with other COVID-19 confirmed patients, the incubation period (if the patient remembers any contact history) of the illness. History of any risk factors such as hypertension, diabetes, smoking, cardiovascular disease, or renal, hepatobiliary, gastrointestinal tract, neurological, hematological, and malignant diseases or use of any immunosuppressive medications were taken (17). All the patients were contacted by phone when there was any missed information in their case sheets.

\section{Patient consent and ethical approval}

The study was completed following the declaration of Helsinki in which the aims of the study were explained to those who already agreed to participate and gave their verbal consent. The study was approved by the College of Medicine, University of Sulaimani, Sulaimaniyah, Iraq with the approval number MED-UoS-05-2021.

\section{Patient's category}

The patients were subdivided into 2 severity groups according to the need for hospitalization or respiratory support as follows:

1. Non-hospitalizedgroup: mild to moderate cases were treated at home without the need for $\mathrm{O}_{2}$ supply.

2. Hospitalized group: Severe cases were treated at the hospital; need $\mathrm{O}_{2}$ alone or with respiratory support by CPAP or mechanical ventilator.

For comparison purposes, data about ABO blood type distribution in normal population were obtained retrospectively from 1698 visitors of Sulaimaniyah central laboratory during a similar period in the year before the COVID-19 pandemic.

\section{Statistical analysis}

The data were analyzed using Statistical Package for Social Sciences (SPSS IBM-version 21.0) software. Descriptive statistics were presented as mean \pm SD (standard deviation) and frequencies were expressed as percentages. Chi-square for categorical variables and t-test were used to compare between two means. The level of significance ( $p$-value) was set at $\leq 0.05$. 


\section{Results}

The study enrolled 530 COVID-19 cases with a mean age of $43.58 \pm 15.91$ in which males were affected more than females (234 vs. 296 patients, respectively).

ABO groups comparison between the healthy controls and COVID-19 patients

The distribution of ABO blood groups in COVID-19 patients as compared to healthy non-COVID-19 patients did not show any significant differences (Table 1 ).

Table 1

ABO type distribution between healthy controls and COVID-19 patients.

\begin{tabular}{|llll|}
\hline ABO Groups & $\begin{array}{l}\text { Heathy Controls } \\
\text { No. }(\%)\end{array}$ & $\begin{array}{l}\text { COVID-19 patients } \\
\text { No. }(\%)\end{array}$ & P-value* \\
\hline A- & $53(3.21 \%)$ & $20(3.77 \%)$ & 0.46 \\
\hline A+ & $507(29.85 \%)$ & $159(31.36 \%)$ & 0.94 \\
\hline B- & $28(1.64 \%)$ & $6(1.13 \%)$ & 0.39 \\
\hline B+ & $320(18.84 \%)$ & $99(18.68 \%)$ & 0.93 \\
\hline AB- & $6(0.35 \%)$ & $4(0.75 \%)$ & 0.22 \\
\hline AB+ & $99(5.83 \%)$ & $31(5.84 \%)$ & 0.99 \\
\hline O- & $42(2.47 \%)$ & $12(2.26 \%)$ & 0.78 \\
\hline O+ & $643(37.86 \%)$ & $199(37.54 \%)$ & 0.92 \\
\hline Total & 1698 & 530 & \\
\hline * Chi-square test & & \\
\hline
\end{tabular}

\section{Comparisons Between Hospitalized Vs. Non-hospitalized Covid-19 Patients}

There were significant differences among ABO groups $(p<0.0001)$ in regards to the severity in form of the need for hospitalization and $\mathrm{O}_{2}$ supplementation. Blood group $\mathrm{A}$ needed hospitalization more than other blood groups $(38 \%, p=0.001)$ while, the $B$ group revealed the lowest need to be hospitalized $(30.5 \%)$ (Table 2). 
Table 2

The association of ABO types with severity of COVID-19 infection (Hospitalized vs. Non-hospitalized).

\begin{tabular}{|llll|}
\hline ABO Groups & $\begin{array}{l}\text { Hospitalized } \\
n=184\end{array}$ & $\begin{array}{l}\text { Non-hospitalized } \\
n=346\end{array}$ & P-value* \\
\hline$A(n=179)$ & $68(38.0)$ & $111(62.0 \%)$ & 0.001 \\
\hline$B(n=105)$ & $32(30.5)$ & $73(69.5)$ & $<0.0001$ \\
\hline$A B(n=35)$ & $13(37.0)$ & $22(62.9)$ & 0.12 \\
\hline$O(n=211)$ & $71(33.6)$ & $140(66.4)$ & $<0.0001$ \\
\hline P-value* & $<0.0001$ & $<0.0001$ & \\
\hline * Chi-square test & & \\
\hline
\end{tabular}

\section{Demographic, Clinical, And Prognostic Factors}

Table 3 shows the mean age of the hospitalized patient that was older than non-hospitalized patients. Females were admitted more than males $(p<0.0001$ and $p<0.002$, respectively). The duration of COVID19 illness, the need for plasma, and the rate of mortality were very significantly higher among hospitalized COVID-19 patients than non-hospitalized, with $p<0.0001, p<0.001$, and $p<0.0001$, respectively). 
Table 3

Comparison of some demographic, clinical and prognostic factors between hospitalized and non-hospitalized patients.

\begin{tabular}{|llll|}
\hline Variables & $\begin{array}{l}\text { Hospitalized } \\
(\mathbf{n = 1 8 4})\end{array}$ & $\begin{array}{l}\text { Non-Hospitalized } \\
(\mathbf{n = 3 4 6})\end{array}$ & P-value* \\
\hline Age & $53.90 \pm 17.09(\%)$ & $38.07 \pm 13.45$ & $<0.0001$ \\
\hline Male & $119(64.67 \%)$ & $177(33.81 \%)$ & 0.002 \\
\cline { 1 - 3 } Female & $65(35.33 \%)$ & $169(48.84 \%)$ & \\
\hline Contact history & $156(84.87 \%)$ & $309(89.30 \%)$ & 0.13 \\
\hline Incubation period & $5.57 \pm 4.33$ & $5.45 \pm 4.08$ & 0.82 \\
\hline Duration of illness & $22.38 \pm 13.03$ & $14.58 \pm 8.38$ & $<0.0001$ \\
\hline Need plasma & $54(29.34 \%)$ & $1(0.28 \%)$ & $<0.001$ \\
\hline Complication & $69(37.50 \%)$ & $113(32.65 \%)$ & 0.26 \\
\hline Passed patients & $38(20.65 \%)$ & $0(0.00 \%)$ & $<0.0001$ \\
\hline Alive patients & $146(79.35 \%)$ & $346(100.00 \%)$ & \\
\hline * Chi-square test & & & \\
\hline
\end{tabular}

\section{Gender Effect On Some Parameters}

According to Table 4, the mean age of male COVID-19 patients was older than females with a highly significant difference $(p=0.005)$, and the duration of illness was more prolonged $(p=0.05)$. There were no differences between the 2 gender regarding; incubation period, BMl, or mortality $(p>0.05)$.

Table 4

Gender impact on some of the studied parameters.

\begin{tabular}{|llll|}
\hline Parameters & Male $\mathrm{n}=\mathbf{2 9 6}$ & Female $\mathrm{n}=\mathbf{2 3 4}$ & P-value* $^{*}$ \\
\hline Age & $45.19 \pm 15.20$ & $41.03 \pm 17.34$ & 0.005 \\
\hline Duration of Illness & $18.03 \pm 11.65$ & $16.22 \pm 8.42$ & 0.05 \\
\hline Incubation Period & $5.50 \pm 3.97$ & $5.41 \pm 3.86$ & 0.43 \\
BMl & $25.99 \pm 3.16$ & $25.48 \pm 4.21$ & 0.34 \\
\hline Death & $18(6.0 \%)$ & $20(8.5 \%)$ & 0.27 \\
\hline * Chi-square test & & & \\
\hline
\end{tabular}




\section{Percentages Of Different 1st Symptoms Of Covid-19 Patients}

In $37.2 \%$ of COVID-19 patients, the initial presentation was a combination of more than one symptom. For mono-symptomatic, 1st (initial) presentation as myalgia was the most common documented symptom $(28 \%)$, while dry cough, malaise, shortness of breath (SOB), and fatigue were the least monosymptomatic presentation (Figure 1).

\section{Discussion}

The highest rate of hospitalization in blood group A when compared with other groups can be attributed to the extra sugar $\mathrm{N}$-acetyl galactosamine, on the blood group A cells surface. Furthermore, SARS-CoV is considered one of them, which showed a positive connotation with blood group A with a great number of positive cases in this blood group. This result is in agreement with the result reported by Cooling (18), perhaps proposing extra pathogen contact. This sugar is lost or fewer existing in other blood group cells (18).

As well as, the lowest infection rate and the need for hospitalization in group B, perhaps return to the connotation of the spike (S) protein of SARS-CoV-2, a transmembrane protein, that has been exposed with receptor-binding domain (ACE2) protein which deeds as its cellular receptor (19). As commended in the past for SARS-CoV (20), the linkage of spike protein to the ACE2 receptor on the host cell surfaces may be repressed by the occurrence of anti-A antibodies. Though, this may be factual for blood group $B$, if the $S$ protein of $A, B$, or $A B$ groups transmits respective glycan antigens. It is conceivable that binding of the particular antibodies can chunk the interaction between ACE2 and S protein, thus donation incomplete or complete protection (21). It is similarly thought that once the infection is completely established, it then duplicates in the individual's epithelial cells and therefore displays that individual's antigen, interpreting the individual's antibodies ineffective (21).

Furthermore, in the current study, group A needed hospitalization and $\mathrm{O}_{2}$ more than other blood groups may be regarded as a blood group with an augmented risk attendant with respiratory failure and rising cardiovascular diseases as informed by several studies (22). The A antigen could defend P-selectin and intercellular cell adhesion molecule 1 (ICAM1) from enzymatic cleavage by stimulating longer and stronger binding of leukocytes to them on the vascular wall; more joining molecules devoted to the endothelial cells would on one hand surge inflammation and adhesion but on the other hand, reducing circulation. These jointly predispose type A carriers to a higher likelihood of rising cardiovascular diseases and cumulative disease situations once lead to more demand to $\mathrm{O}_{2}$ these individuals were exposed to redox stresses such as in the case of virus infection (23). While the group 0 phenotype may have deleterious penalties for patients result from inactivation of the A1 glycosyltransferase gene in addition to some unrecognized blood proteins might have a vital role for COVID-19 severity of infection besides $A B O$ blood antigens, in otherwise, A genome-wide association study reported that blood type 0 
subjects have an augmented interleukin 6 (IL-6) level than other blood types do (24). IL-6 is a proinflammatory cytokine encouraging the release of acute-phase proteins like C-reactive protein (CRP). This theory may suggest the shortcoming of being a blood type 0 carrier and may clarify the bad prognosis of type $\mathrm{O}$ blood group patients that needed more respiratory support, this result agreed with Naitza et al. (24).

Whereas, the $\mathrm{B}$ group revealed the lowest need to be hospitalized and $\mathrm{O}_{2}$ demand may be explained by Anti-A antibodies that may prevent the interaction between the viral spike glycoproteins and cellular ACE2 receptors lead to inhibit the pass of the SARS-CoV-2 virus into cells and neutralize the virus in a complement-dependent way. It may also encourage cytotoxic $T$ cells and the acquisition of immunity against other viral antigens (25).

The male COVID-19 patients were older than females and showed a highly significant difference in duration of illness, as well as their rate of mortality, which was much higher. This observation may be attributed to that in the COVID-2019 pandemic, much emphasis was initially placed on the elderly, and now attractively clear that being a male is also a risk factor. The epidemiological outcomes described across different parts of the world showed higher mortality and morbidity in males than females and this result regarded to several factors such as higher expression of ACE 2 receptors for coronavirus in males than females and sex-based immunological differences driven by sex hormone and the $\mathrm{X}$ chromosome. Furthermore, a large part of this difference in the number of deaths is caused by gender behavior (lifestyle), i.e., higher levels of smoking among men compared to women (26).

In the current study the duration of COVID-19 illness, the need for plasma, and the rate of mortality were very significantly higher among hospitalized COVID-19 patients than non-hospitalized. This outcome may be regarded to the relations of the ABO typing with the severity of COVID-19 symptoms, risk of hospitalization, and ventilator support as well as the rate of mortality (5).

On the other hand, our result revealed that in $37.2 \%$ of COVID-19 patients; the initial presentation was a combination of more than one symptom. For mono-symptomatic; 1 st (initial) presentation myalgia was the most common than other symptoms. This result agreed with the result reported by Rothan and Byrareddy (27). They mentioned early COVID-19 symptoms were a combination and included headache, fever, dry cough, dyspnea, and myalgia, among other similar ones to another viral respiratory disease.

\section{Conclusion}

The study concluded that the group blood of $A$ was associated with the highest infection rate and need the hospitalized and $\mathrm{O}_{2}$ in addition to the higher duration of illness as well as the rate of mortality in male COVID-19 patient was more than females.

\section{Declarations}


The authors are showing utmost appreciation to the staff of the Qala (at Kalar province), Shaheed Aso, and Shaheed Dr. Hemn hospitals for Corona in Sulaimaniyah city, Iraqi Kurdistan region for their kind help and support to this research study.

\section{Consent for publication}

Written inform consent was obtained from the patients for publication.

\section{Availability of data and materials}

All data generated or analyzed during this study are included in this published article.

\section{Funding}

This research did not receive any specific grant from any funding agency in the public, commercial, or not-for-profit sector.

\section{Authors' contributions}

N.A.O. and M.S.M. conducted the research work, S.J.A. analyzed the data and performed the statistical analysis, H.S.R. edited, revise, corrected, and submitted the manuscript. All authors were participated in the writing the original draft of the manuscript.

\section{Competing interests}

The authors declare that they have no competing interests.

\section{References}

1. Genomewide Association Study of Severe Covid-19 with Respiratory Failure. N Engl J Med. 2020;383(16):1522-34.

2. Ali ZA, El-mallakh RS. Since January 2020 Elsevier has created a COVID-19 resource center with free information in English and Mandarin on the novel coronavirus COVID- 19. The COVID-19 resource center is hosted on Elsevier Connect, the company's public news and information. 2020.

3. COVID 19 rapid evidence summary: Remdesivir for treating hospitalized patients with suspected or confirmed COVID-19. 2020;1-6. Available from: https://www.nice.org.uk/advice/es27/resources/covid-19-rapid-evidence-summary-remdesivir-fortreating-hospitalised-patients-with-suspected-or-confirmed-covid19-pdf-1158180847045

4. COVID-19 rapid evidence summary: Remdesivir for treating hospitalized patients with suspected or confirmed COVID-19 Key messages,1-6.

5. Wu Y, Feng Z, Li P, Yu Q. Since January 2020 Elsevier has created a COVID-19 resource center with free information in English and Mandarin on the novel coronavirus COVID- 19. The COVID-19 resource center is hosted on Elsevier Connect, the company's public news and information. 2020. 
6. Zhao J, Yang Y, Huang H-P, Li D, Gu D-F, Lu X-F, et al. Relationship between the ABO Blood Group and the COVID-19 Susceptibility. medRxiv. 2020;

7. GÖKER H, ALADAĞ-KARAKULAK E, DEMIROĞLU H, AYAZ CM, BÜYÜKAŞIK Y, INKAYA AC, et al. The effects of blood group types on the risk of COVID-19 infection and its clinical outcome. TURKISH J Med Sci. 2020;50(4):679-83. Available from: http://online.journals.tubitak.gov.tr/openDoiPdf.htm? mKodu=sag-2005-395

8. Garratty G. Association of blood groups and disease: do blood group antigens and antibodies have a biological role? Hist Philos Life Sci. 1996;18(3):321-44.

9. Garratty G. Blood Groups and Disease: A Historical Perspective. 2000;4(4):291-301.

10. Clausen H, Hakornori S. ABH and Related Histo-Blood Group Antigens; Immunochemical Differences in Carrier Isotypes and Their Distribution '. 1989;1-20.

11. Li J, Wang X, Chen J, Cai Y, Deng A, Yang M. Association between ABO blood groups and risk of SARS-CoV-2 pneumonia. Br J Haematol. 2020;190(1):24-7.

12. Cheng Y, Cheng G, Chui $\mathrm{CH}$, Lau FY, Chan PKS, Ng MHL, et al. ABO blood group and susceptibility to severe acute respiratory syndrome [5]. Vol. 293, Journal of the American Medical Association. 2005. p. $1450-1$.

13. Li J, Wang X, Chen J, Cai Y, Deng A, Yang M. Association between ABO blood groups and risk of SARS-CoV-2 pneumonia. Br J Haematol. 2020, 26;190(1):24-7. Available from: https://onlinelibrary.wiley.com/doi/abs/10.1111/bjh.16797

14. Wu Y, Feng Z, Li P, Yu Q. Relationship between ABO blood group distribution and clinical characteristics in patients with COVID-19. Clin Chim Acta [Internet]. 2020;509:220-3. Available from: https://linkinghub.elsevier.com/retrieve/pii/S0009898120302904

15. Corman VM, Landt O, Kaiser M, Molenkamp R, Meijer A, Chu DK, et al. Detection of 2019 -nCoV by RTPCR. Euro Surveill. 2020;25(3):1-8.

16. Agostini A, Floridi C, Borgheresi A, Badaloni M, Esposto Pirani P, Terilli F, et al. Proposal of a low-dose, long-pitch, dual-source chest CT protocol on third-generation dual-source CT using a tin filter for spectral shaping at $100 \mathrm{kVp}$ for CoronaVirus Disease 2019 (COVID-19) patients: a feasibility study. Radiol Medica. 2020;125(4):365-73. Available from: https://doi.org/10.1007/s11547-020-01179-x

17. Brookmeyer R. Incubation Period of Infectious Diseases. In: Wiley StatsRef: Statistics Reference Online. Chichester, UK: John Wiley \& Sons, Ltd; 2015. p. 1-8. Available from: http://doi.wiley.com/10.1002/9781118445112.stat05241.pub2

18. Cooling L. Blood groups in infection and host susceptibility. Clin Microbiol Rev. 2015;28(3):801-70.

19. Glycoprotein C-S, Walls AC, Park Y, Tortorici MA, Wall A, Mcguire AT, et al. Structure, Function, and Antigenicity of the SARS- Structure, Function, and Antigenicity of the SARS-CoV-2 Spike Glycoprotein. Cell. 2020;181(2):281-292.e6. Available from: http://dx.doi.org/10.1016/j.cell.2020.02.058

20. Guillon P, Cl M, Chou C, Ruvo N, Pendu J Le. Inhibition of the interaction between the SARS-CoV Spike protein and its cellular receptor by anti-histo-blood group antibodies. 2008;18(12):1085-93. 
21. Yamamoto F. ABO Blood Groups and SARS-CoV-2/COVID-19 Infection (version 2) by Fumiichiro Yamamoto. 2020;(August).

22. Article $\mathrm{O} . \mathrm{ABO}(\mathrm{H})$ blood groups and vascular disease: a systematic review and meta-analysis. 2008;:62-9.

23. Chasman DI, Kellogg M, Zee RYL, Rifai N, Badola S, Miletich JP, et al. Novel Association of ABO Histo-Blood Group Antigen with Soluble ICAM-1: Results of a Genome-Wide Association Study of 6, 578 Women. 2008;4(7).

24. Naitza S, Porcu E, Steri M, Taub DD, Mulas A, Xiao X, et al. A Genome-Wide Association Scan on the Levels of Markers of Inflammation in Sardinians Reveals Associations That Underpin Its Complex Regulation. 2012;8(1).

25. Klok FA, Kruip MJHA, Meer NJM Van Der, Arbous MS, Gommers DAMPJ, Kant KM, et al. Incidence of thrombotic complications in critically ill ICU patients with COVID-19. Thromb Res. 2020;191:145-7. Available from: https://doi.org/10.1016/j.thromres.2020.04.013

26. Bwire GM. Coronavirus: Why Men are More Vulnerable to Covid-19 Than Women ? 2020;8-10.

27. Rothan HA, Byrareddy SN. The epidemiology and pathogenesis of coronavirus disease (COVID-19) outbreak. J Autoimmun. 2020:102433. Available from: https://doi.org/10.1016/j.jaut.2020.102433

\section{Figures}

\section{Percentage of 1st symptom}

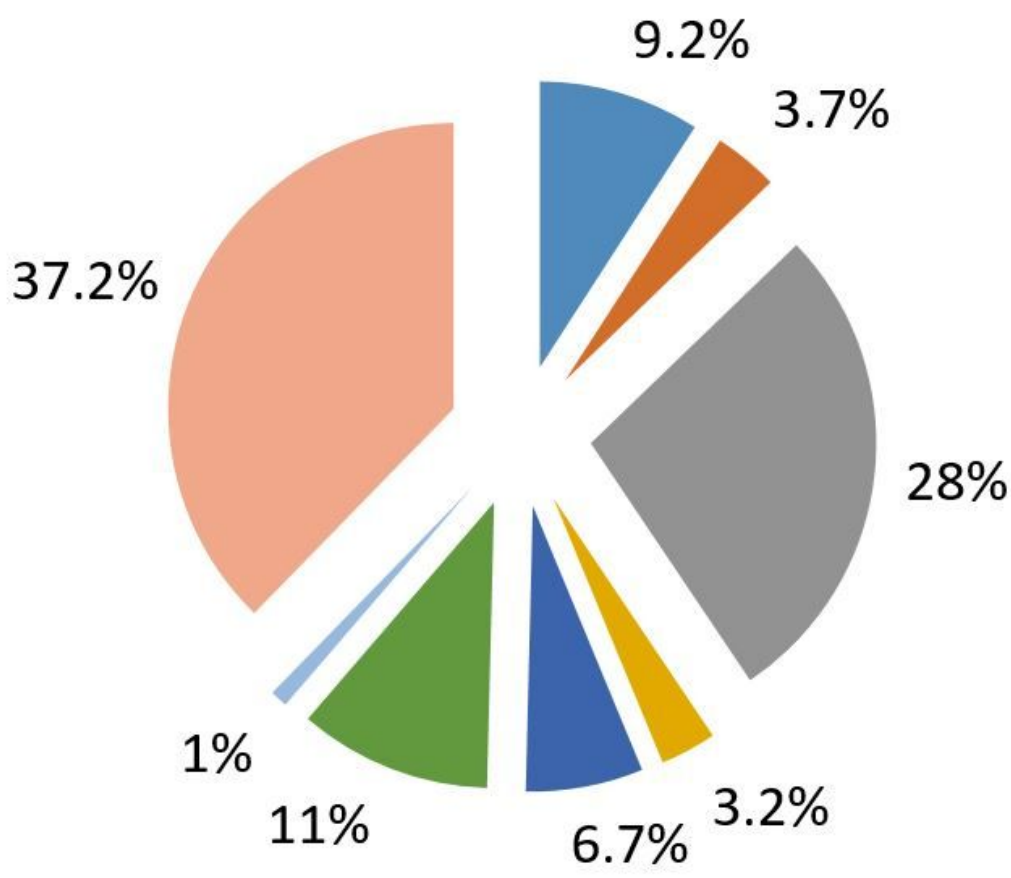

Headach

Malaise

Myalgia

SOB

Dry Cough

Fever

Fatigue

Combined 


\section{Figure 1}

The distribution of the 1st symptom among COVID-19 patients. 